\title{
LAÜE BACK-REFLECTION METHOD FOR CRYSTALLOGRAPHIC ORIENTATION OF A MARTENSITIC Cu-Zn-AI SINGLE CRYSTAL OF THE MONOCLINIC SYSTEM
}

\author{
Uíslei Carlos Zambrano, Matildes Blanco, Nilso Barelli and Assis Vicente Benedetti* \\ Departamento de Físico-Química, Instituto de Química, Universidade Estadual Paulista, CP 355, 14801-970 \\ Araraquara - SP, Brasil \\ Javier Fernández \\ CPT Thermal spray Center, Materials Engineering, Dept. Ciencia dels Materials y Enginyeria Metal-lúrgica, Universitat de \\ Barcelona, C/ Martí i Franqués 1, E-08028 Barcelona, Spain
}

Recebido em 13/4/06; aceito em 18/5/07; publicado na web em 19/12/07

\begin{abstract}
A martensitic single crystal Cu-23.95Zn-3.62(wt.\%)Al alloy was obtained melting pure $\mathrm{Cu}, \mathrm{Zn}$ and $\mathrm{Al}$ using Bridgman's method. The martensitic phase (monoclinic) can present up to 24 variants, and orienting the surface according to a certain plane is a very hard task. The single crystal was submitted to 8 tons of tension (stress) along the longitudinal direction to reduce the number of variants and facilitate the surface orientation according to the desired plane. This single crystal was oriented using the Laüe backreflection method to give surfaces with the following oriented crystallographic planes: (010), (120) and (130). It was observed that the tension stress was applied along the [010] direction.
\end{abstract}

Keywords: single crystal orientation; copper-based alloy; Laüe back-reflection method.

\section{INTRODUCTION}

The electrochemical behavior of copper-based alloys and their pure elements has been studied for many years by the authors in alkaline, salt and acid solutions ${ }^{1-10}$. These studies were conducted only with mono- or polyphasic polycrystalline alloys in the following metallurgical conditions: as cast, annealed, quenched or submitted to other heat treatments. Many results obtained for these metallic alloys were strongly influenced by copper, the majority element. For $\mathrm{Cu}-\mathrm{Al}-\mathrm{Ag}$ alloys, depending on the media and silver or aluminum concentration, the electrochemical behavior was influenced by silver ${ }^{1-}$ $3,6,8$ or even controlled by aluminum ${ }^{4,7,10}$. The electrochemical response obtained with such polycrystalline materials is determined by the contribution of all crystalline planes present on the electrode surface and exposed to the solution. To go deeper on electrochemical studies of these copper-based alloys it was decided to study orientated single crystal of these materials.

Due to the difficulties to buy single crystals of copper-based alloys with a desired composition, a furnace previously described ${ }^{11}$ was modified and constructed ${ }^{12}$ in our laboratories to obtain single crystals based on the Bridgman's method ${ }^{13}$. Our studies began with an easier crystallographic system, a single crystal $\beta$ phase $\mathrm{Cu}-\mathrm{Zn}$ $\mathrm{Al}$ alloy, which belongs to the $\mathrm{DO}_{3}$ ordered structure. Single crystals were orientated in the (111), (110) and (100) crystallographic planes ${ }^{12,14}$, using the Laüe back-reflection method ${ }^{15,16}$. Considering our interest in shape memory copper-based alloys ${ }^{17-19}$, simultaneously to the $\beta$ phase $\mathrm{Cu}-\mathrm{Zn}-\mathrm{Al}$ preparation, martensitic $\mathrm{Cu}-\mathrm{Zn}-\mathrm{Al}$ single crystals were also obtained. Martensitic structures can also be originated from the $\beta$ phase structure.

Starting from original $\beta$ phase single crystal (body-centered cubic crystalline system) a martensitic phase can be obtained by cooling, and 24 martensite variants can be formed to selfaccommodating. For instance, beginning with the plane present in the original phase, habitual planes found in the martensitic phase

*e-mail: benedeti@iq.unesp.br can be calculated. With stereographic projection 6 groups of these planes were found, each one with 4 variants or clusters around each plane. It is the case of the transformation from the original $\beta$ phase $\left(\mathrm{DO}_{3}\right)$ to $18 \mathrm{R}_{1}$ martensite $\left(\beta^{\prime}\right)$. Then each one of the 6 groups has 2 opposite directions itself and 2 equivalents because the variants are twinned, and 24 variants of martensitic structure single crystal are formed $^{20,21}$. These can be described starting from orthorhombic unit cells and showing some distortion (monoclinic distortion) when compared to the perfect pilling up of the original phase ${ }^{22}$. The martensitic transformation occurs by shearing, also called invariant tension of the plane. Its product generates invariant tension in the lattice, producing defects such as twinned plates, stack defects and/ or dislocations ${ }^{23,24}$.

Metals and metallic alloys with these characteristics respond to the tension applied by sliding the plates and this process can be reversible; unlikely most of the metals do not show this transformation. A variant or a single way plates movement can be preferably formed, depending on the manner and form that martensitic materials are submitted to the tension stress. This fact is related to the sliding of the martensitic plates, which respond and interact with the applied tensile force used to obtain variants in a specific direction. This observation is a consequence of the lattice reversibility between the original phase and the martensitic one. The accommodation of the plates by means of non-diffusional displacements allows the conversion of one to another crystallographic system and vice-versa. This transformation can also be achieved by heating and cooling the $\mathrm{Cu}-\mathrm{Zn}-\mathrm{Al}$ alloy. This reversibility also characterizes the pseudo-elasticity of the material, which plays an important role in technological applications ${ }^{20}$.

The $\mathrm{Cu}-\mathrm{Zn}-\mathrm{Al}$ as well as other alloys, metals and materials are not always isotropic in their physical properties. An example is the module of elasticity (Young's module) that changes with the crystallographic direction. Therefore, determining the orientation of a single crystal that will be submitted to some mechanical test to verify the relationship between a specific property and its crystallographic orientation is necessary. 
The Laüe back-reflection method can be used to orientate a single crystal to expose a specific plane at the surface. This method consists in analyzing a group of diffraction points (called spots) produced on the film, since the positions of these points are determined by the crystal orientation. It is used because a special preparation of the sample is not required and there is no thickness restriction, while the transmission method needs thin samples with small absorption ${ }^{15,25}$.

In the Lauie back-reflection method, the sample begins to be orientated in relation to the film that has a square or rectangular form and a reference mark in one end of the film. For metallurgical purposes the shapes of single crystal samples are wires, stalks (sticks), foils or plates ${ }^{25}$. In the Lauie back-reflection method, the planes of a zone are as beams that draw a conical surface, in which the axis is the zone axis and is tilted in relation to the incident beam forming a semi-vertex angle. Therefore, the diffraction on a Laüe back-reflection film comes as hyperboles or straight lines corresponding to the tilting of the zone axis ${ }^{25}$.

To determine the plane normal coordinates from the measured coordinates of the diffraction spot on the film a graphical method was devised by Greninger, who developed a chart ${ }^{25}$. When the center of the chart is placed in the center of the film the coordinates $\gamma$ and $\delta$ of the plane normal are directly provided by the position (in terms of $\mathrm{x}$ and $\mathrm{y}$ ) of any corresponding diffraction and in any distance (D) between the sample and the film ${ }^{25}$. The Greninger's chart is graduated in intervals of $2^{\circ}$, drawing hyperbolic lines on a transparent sheet support and giving directly the angular coordinates of the plane normal causing the $\operatorname{spot}^{15,25}$. Using the Greninger's chart the spots in the Laüe's film is transported to the Wulff net and the crystallographic orientation of the single crystal can be obtained. This method was used to described the crystallographic orientation of single crystals belonging to a cubic system ${ }^{15,26,27}$. However, the use of Lauie back-reflection method to orientate the single crystals belonging to the monoclinic system, such as minerals, metals or metallic alloys including copper-based martensitic samples, was not found in the literature. Then, the goal of this work is to show how one can orientate a single crystal of monoclinic system without using any sophisticated method or software.

No stereographic projection pattern for single crystals of the monoclinic system was found which could help the interpretation of the diffraction pattern or its orientation. So, the aim of this work is to determine the crystallographic orientation of a monoclinic system such as martensitic single crystals of $\mathrm{Cu}-\mathrm{Zn}-\mathrm{Al}$ alloy which were submitted to tension stress in order to reduce the number of variants. Considering that this structure shows some difficulty to be orientated due to the low symmetry of the crystalline system, details to obtain stereographic projection for this system and the manner to orientate single crystals in (010), (120) and (130) crystallographic planes are clearly described. These single crystals have been used for electrochemical studies. Therefore, this work can present an important contribution to the field and to many electrochemists who intend to study non-commercially available single crystals. Also, very simple and low cost equipments are needed.

\section{EXPERIMENTAL}

\section{The $\mathrm{Cu}-\mathrm{Zn}-\mathrm{Al}$ alloy preparation}

The $\mathrm{Cu}-23.95 \mathrm{Zn}-3.62($ wt.\%)Al alloy was prepared by placing pure copper, zinc and aluminum elements inside a quartz blister sealed under vacuum, and by melting in an inductance furnace at $1400{ }^{\circ} \mathrm{C}$. The cylinder of the polycrystalline alloy obtained was cut in little pieces and put in another quartz blister sealed under vacuum.
The blister was placed in a modified Bridgman's furnace constructed in our laboratory ${ }^{12}$ and the material was slowly run through the longitudinal axis of the furnace where the alloy was remelted and the single crystal was obtained.

\section{Crystal characterization and orientation}

Initially, the single crystal was polished and etched with $\mathrm{FeCl}_{3}$ alcoholic solution $\left(5 \mathrm{~g} \mathrm{FeCl}_{3}+30 \mathrm{~cm}^{3} \mathrm{HCl}\right.$ concentrated $+30 \mathrm{~cm}^{3}$ isoamylic or isopentylic alcohol $+30 \mathrm{~cm}^{3}$ ethyl alcohol $+5 \mathrm{~cm}^{3}$ distilled water) for different times to reveal the presence of one or more than one crystal. Using optical microscope this sample was analyzed and many variants were observed, which made the crystal orientation almost impossible since any variant diffracts as a single crystal. To solve this problem the single crystal was streched applying a tensile force of $8 \mathrm{t}$ in the longitudinal direction of the cylinder (15 cm length) to reduce the number of variants from 24 to one, which was confirmed after repeating the etching on the stretched crystal followed by OM analysis.

\section{Diffraction system for crystal orientation}

A Rigaku X-ray generator, serial UX 10031, with a tube of copper was used for crystallographic studies. To reduce the exposure time the X-rays tubes must have an anti-cathode that produces high white radiation and operates close to 30 or $35 \mathrm{kV}$. Tubes of $\mathrm{W}$, Mo or Ag are also appropriate. A Laüe camera with a collimator and goniometer with a large angular freedom degree $\left(18^{\circ}\right)$ in $\mathrm{X}$ and $\mathrm{Y}$ completed the diffraction system.

\section{Crystal orientation}

The sample was orientated in relation to the rectangular film supplied by Kodak (mammography film), in which a reference mark was made in one end of the film. Afterwards, the crystal was exposed to the $\mathrm{X}$-ray beam ( $\mathrm{Cu}$ white radiation) operating at $35 \mathrm{kV}$ and 20 $\mathrm{mA}$ for $30 \mathrm{~min}$. Then, the film was developed and fixed using appropriate solutions prepared in our laboratory.

The developed Laüe back-reflection film contains a great number of diffraction spots, which represent the planes that diffract the X-ray beam. The families of planes that were in the diffraction position are responsible for diffracting X-ray beams. Considering that the film is positioned $3 \mathrm{~cm}$ from the crystal and a film of 127 $\mathrm{x} 180 \mathrm{~mm}$ is used, all planes in the zone whose zone axis is disposed at angles higher than $35^{\circ}$ respect to the X-ray beam will produce spots on the film. The diffraction spots form hyperbolic curves which represent crystallographic zones. Some of these curves possess much more diffraction spots than others, indicating that they represent a larger population of planes of low Miller indices. In order to analyse a group of spots belonging to the same zone the Greninger's chart ${ }^{25}$ can be used.

The Lauie back-reflection film was covered by a transparent sheet fixed on the film. The Greninger's chart was placed on the center of the film which has a mark to identified the correct possition to be interpreted. Afterwards, the coordinates of the diffraction spots were directly read on the chart and these coordinates were placed in a stereographic projection with the help of a Wulff net. It is extremely important to put the meridians in the position from West to East ${ }^{25}$. From the points localized in the same meridian (zone), all zones and zone axis were found and the angles between the zone axis were measured. For a cubic system these values can be directly compared with those already published ${ }^{25}$.

However, in the case of monoclinic system no zone axis and angles between the zone axis values were published. So, considering the parameters of the unit cell for the single crystal here studied, 
the interplanar angles for a large number of planes were calculated using a software ${ }^{28}$. The results were used to construct the stereographic projection in the [001] direction, since no projection pattern for helping the diffraction interpretation exists.

After many attempts the desired crystal orientation can be found and the crystal must be fixed in the goniometer to be polished or cut without losing the orientation. To fix the orientated crystal on the goniometer, resin was applied and left resting for $24 \mathrm{~h}$ to impede any movement of the Teflon piece and of the crystal during the polishing or cutting of the sample. The goniometer was inserted in a cylinder of stainless steel, $5 \mathrm{~cm}$ height and $5 \mathrm{~cm}$ inner diameter ( $5.8 \mathrm{~cm}$ outer diameter), with three teeth properly projected to make an angle of 90 degrees with the surface of the sandpaper. It allowed the sample to be polished in the same angle in which it was adjusted.

\section{RESULTS AND DISCUSSION}

\section{Characterization of martensitic $\mathrm{Cu}-\mathrm{Zn}-\mathrm{Al}$ single crystal}

The studied sample was obtained from a single crystal $\mathrm{Cu}-$ 23.95Zn-3.62(wt.\%)Al alloy, monoclinic system and martensitic structure prepared as described in the experimental section. The parameters of unit cell previously obtained are: $\mathrm{a}_{0}=4.420 \AA, \mathrm{b}_{0}=$ $5.323 \AA, c_{0}=38.313 \AA, \hat{a}=88.68^{\circ}$. The following equation has been used to get the crystal structure parameters after the reference 25

$\frac{1}{d_{h k l}^{2}}=\frac{1}{\operatorname{sen}^{2} \beta}\left(\frac{h^{2}}{a^{2}}+\frac{k^{2} \operatorname{sen}^{2} \beta}{b^{2}}+\frac{l^{2}}{c^{2}}-\frac{2 h l \cos \beta}{a c}\right)$

Thus, using the (hkl) index of the diffraction peaks, the equation can be solved for giving a, b, c and $\beta$ cell parameters. A typical martensitic structure was observed (Figure 1).

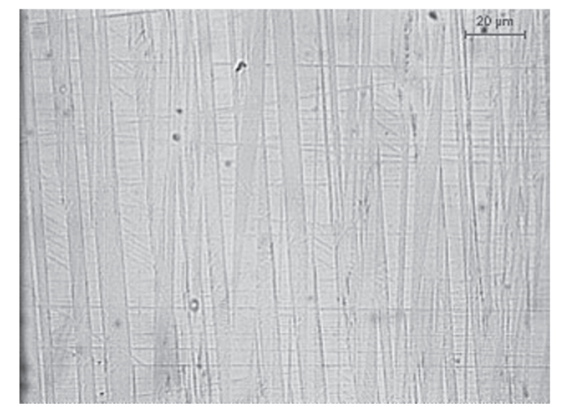

Figure 1. Optical micrograph of the non-orientated martensitic $\mathrm{Cu}-\mathrm{Zn}-\mathrm{Al}$ alloy after revealing the surface with $\mathrm{FeCl}_{3}$ acid alcoholic solution for $1 \mathrm{~s}$. Magnification $500 X$

\section{Crystal orientation}

For monoclinic systems as mentioned above, each crystal has its own stereographic projection. Then, a theoretical projection in the direction of (001) plane was made for the $\mathrm{Cu}-\mathrm{Zn}-\mathrm{Al}$ single crystal using the crystallographic data $a, b$ and $c$ and the $\beta$ angle as shown in Figure 2.

Figure $3 \mathrm{a}$ shows the film obtained during the first exposure of the top of the sample to the X-ray beam. The single crystal diffraction spots were observed with some enlargement due to the tension present in the lattice. Interpretation of the film was practically impossible because no hyperboles (zones) of diffraction exist. As crystallographic principle, the diffraction spots of high intensity are diffractions of planes with low Miller indices. Then,

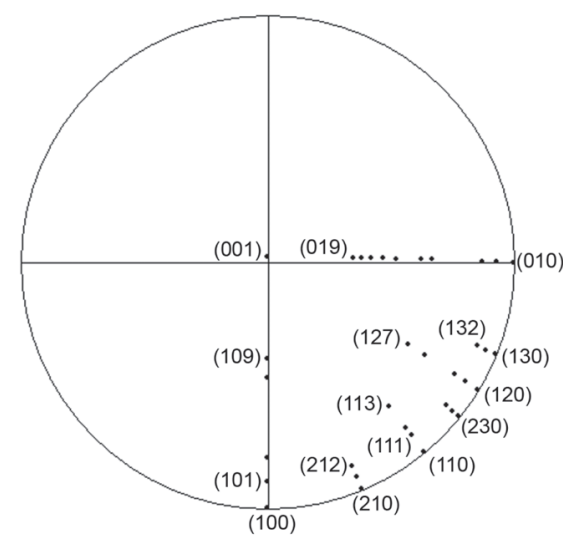

Figure 2. Theoretical stereographic projection on (001) plane using the parameters of the lattice for a single crystal of $\mathrm{Cu}-\mathrm{Zn}-\mathrm{Al}$ alloy

the spot marked in Figure 3a was moved to the center of the film, generating the film of Figure $3 \mathrm{~b}$. Although this film did not show diffraction hyperboles two lines exist (traced zones, Figure 3b), each one joining three diffraction spots and making an angle of $88^{\circ}$ to each other. This angle is the angle between the $a$ and $c$ spots (zones axes) of the stereographic projection shown in Figure 4. This value is almost the same mentioned above for the $\beta$ angle $\left(88.68^{\circ}\right)$. From Figure 4 it was not possible to find a spot for the $b$ parameter that was simultaneously $90^{\circ}$ in relation to spots for the $a$ and $c$ parameters. It means that no plane with low Miller index was found from this exposure of the top of the crystal.
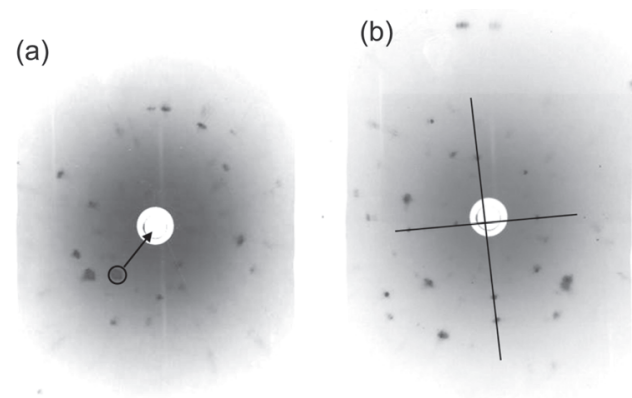

Figure 3. Laüegrams of the martensitic Cu-Zn-Al alloy submitted to a tensile force of 8 tons (a) and after moving the circled spot to the center of the film (b)

Therefore, the longitudinal parts of the crystal were exposed to $\mathrm{X}$-ray beam. After several attempts the film shown in Figure 5 was obtained. The Laüe diffractions are a characteristic of single crystals which represent defined spots resulting in two hyperboles (zones), one at the inferior and the other at the superior part of the film (Figure 5a). Also between the two hyperboles a straight line can be drawn (zone) containing four spots (the lines were drawn to the lauiegram to facilitate the visualization). In this case, no orientated plane with low Miller index was found.

The difficulty present in this system is the low simmetry and also the possible existence of more than one martensitic variant. For monoclinic structure (low symmetry) submitted to stretch, it was expected to obtain a single crystal with few variants, close to an ideal structure with one variant. However, even if a single crystal with few variants is obtained, the difficulty to find the desired orientation is higher than for a single crystal having only one variant. This happens because there is always the possibility that the laüegram shows contribution of other variants. As a consequence, a small change 


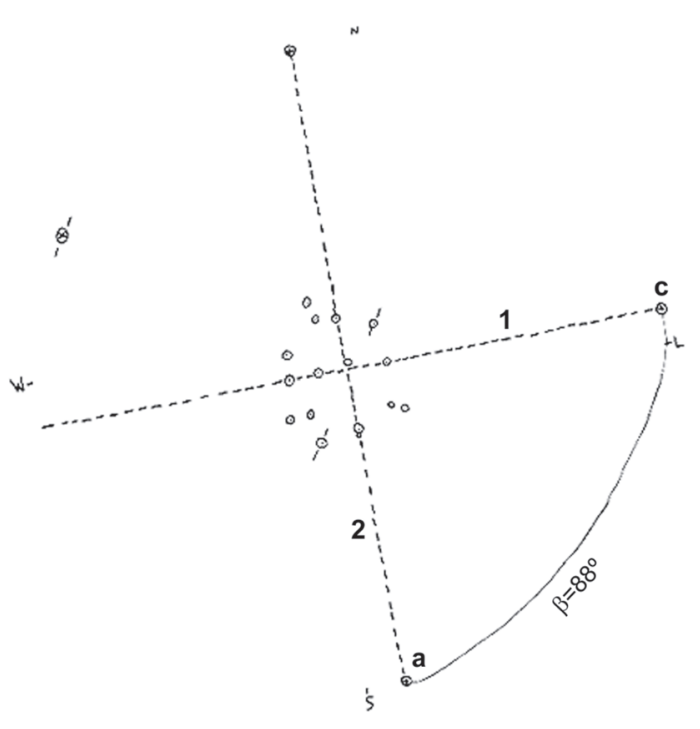

Figure 4. Stereographic projection of the film of Figure $3 b$
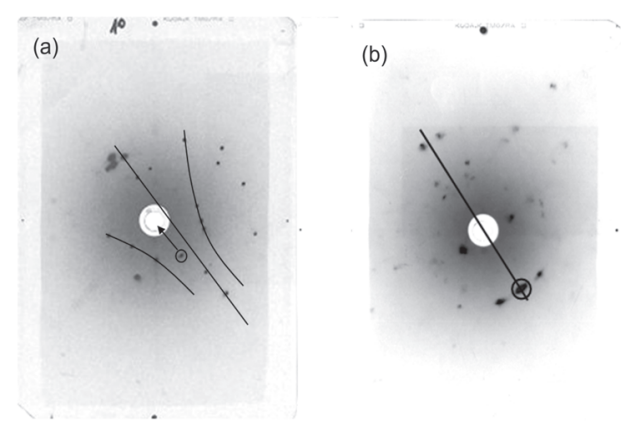

Figure 5. Laüegram of the longitudinal part of the martensitic Cu-Zn-Al single crystal (a) and after moving the circled spot to the center of the film (b)

in the position of the sample to search the desired orientation allows the interference of a new variant, losing all the previous work. One can observe one variant in one field and eventually two in another observed field, which means the possibility of an influence of the second variant in the examined field. In this case, the Laüe diffraction is not similar to that for a material with high symmetry (for example, cubic system in which hyperboles are well defined, making it easier to access low Miller indices), but it is for a system with low symmetry, which can lead to high Miller indices.

When the marked spot of Figure 5a was moved to the center of the film, a new film was obtained (Figure 5b). Now, it is possible to note a certain symmetry when a diagonal line is traced starting from a spot marked with a circle in Figure 5b, passing through the center of the film, where the spot previously marked in Figure 5a is.

With the Greninger's chart the spots present in Figure 5b were transferred to the Wulff net, as showed in Figure 6. Beginning from the zone axis, which coincides with the center of the film $(\mathrm{O})$, the zone 1 was generated. This zone represents the maximum equatorial circle of the Wulff net itself. Zone 2 passes through three diffraction spots in Figure 6 and generates the zone axis represented by $a$. Zone 3 passes through two spots plus the spot in the center of the film and generates the zone axis represented by $c$.

For this monoclinic system, the angles between the lattice parameters are: $90^{\circ}$ between $a$ and $b, 90^{\circ}$ between $b$ and $c$ and $88.68^{\circ}$ between $a$ and $c$, called $\beta$ angle. The $\beta$ angle between $a$ and

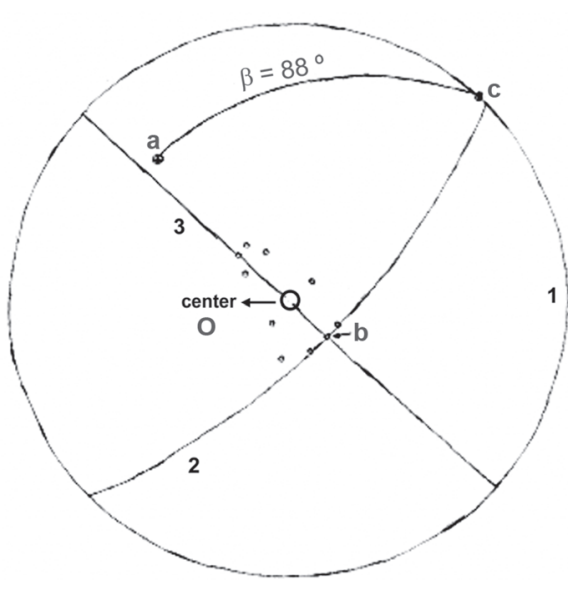

Figure 6. Stereographic projection of the film of Figure $5 b$

$c$ was $88^{\circ}$ (Figure 6), which is close to the value between the $a$ and $c$ parameters. Now, it is necessary to find a spot that corresponds to the $b$ parameter. This parameter must be positioned simultaneously $90^{\circ}$ from $a$ and $c$ in order to satisfy the expected conditions for this monoclinic system. The $b$ parameter shown in Figure 6 was found in the crossing of zones 2 and 3 . As the spot $b$ is shifted from the center of the film the following procedure is necessary to the indexation of the plane located in the center of the film. It was necessary to use the Wull net to find the angles from the center of the film (normal to the plane at the center) to the parameters $a, b$ and $c$. The following values were obtained for these parameters: 69 ${ }^{\circ}, 23^{\circ}$ and $90^{\circ}$, and they are called director angles for each parameter. Then, Haüy's parametric relationships were used to determine the index of the plane that corresponds to the orientation of this single crystal. Using Haüy's parametric relationship, the director angles $\mathrm{Pa}, \mathrm{Pb}$ and $\mathrm{Pc}\left(69^{\circ}, 23^{\circ}\right.$ and $\left.90^{\circ}\right)$ and the lattice parameters $\left(\mathrm{a}_{0}=4.420 \AA, \mathrm{b}_{0}=5.323 \AA, \mathrm{c}_{0}=38.313 \AA\right)$ the following equation was found (Equation 2):

$h: k: l=a_{0} \cos P a: b_{0} \cos P b: c_{0} \cos P c$

which allows to calculate and determine the index of the orientated crystallographic plane.

Introducing the values for $\mathrm{a}_{0}, \mathrm{~b}_{0}, \mathrm{c}_{0}$ and $P a, P b$ and $P c$ in Equation 2 the following relationship is obtained:

$h: k: l=4.420 \cos 69^{\circ}: 5.323 \cos 23^{\circ}: 38.313 \cos 90^{\circ}$

$h: k: l=1.584: 4.900: 0$ (dividing by 1.584 )

The index of the orientated crystallographic plane was

$(h k l)=\left(\begin{array}{lll}1 & 3 & 0\end{array}\right)$

Thus, the orientation of martensitic $\mathrm{Cu}-\mathrm{Zn}-\mathrm{Al}$ single crystal submitted to tensile stress was determined.

In many cases it is difficult to decide which spot must be placed at the center of the film since the index of the plane which is diffracting is unkown. To solve this problem an artifice can be used: it consists in applying a filtered radiation. This kind of filter was chosen because it avoids the absorption of unwanted radiations such as $\mathrm{Cu}_{\mathrm{K} \beta}$ and others longer than 1,5418 angstrons wavelengths, allowing to pass only the $\mathrm{Cu} \mathrm{K} \alpha$ radiation. (The use of filtered radiation does not correspond exactly to the Laüe method). So, the films of Figure 7 were obtained with a few spots. Therefore, the monochromatic 
wavelength imposes that a few planes are in position to diffract (Figure 7a). This procedure allows to measure the diffraction $\theta$ angle to obtain the $\mathrm{d}_{\text {(hkl) }}$ value and the (hkl) of the diffracting plane. In fact an artifice was used to obtain the $\theta$ angle from only one wavelength radiation. Thus, it was possible to identify the $\mathrm{d}_{(\mathrm{hkl})}$ and (hkl) of some spots. The (hkl) for each spot was calculated using Equation 3, Bragg's Equation $4{ }^{25}$ and the following parameters: the radiation wavelength (1.54 $\AA$ ); the distance (D) between the crystal and the film; and the distance from the center of the film to the spot (r).

$\tan (2 \theta)=\frac{\mathrm{r}}{D}$

$\lambda=2 \mathrm{~d} \sin \theta$

where $\theta=$ the angle $\left({ }^{\circ}\right) ; \lambda=$ wavelength $(\mathrm{Cu} \mathrm{K} \alpha=1.54 \AA)$ and $\mathrm{d}_{(\text {hkl) }}$ $=$ interplanar spacing.

Using the webpage "Crystal Planes Spacings and Interplanar angles.htm" ${ }^{28}$ and knowing the $\mathrm{d}_{\mathrm{hkl}}$ values calculated with Equations. 3 and 4, the Miller index (hkl) of the diffracting plane was found (Figure 7b).
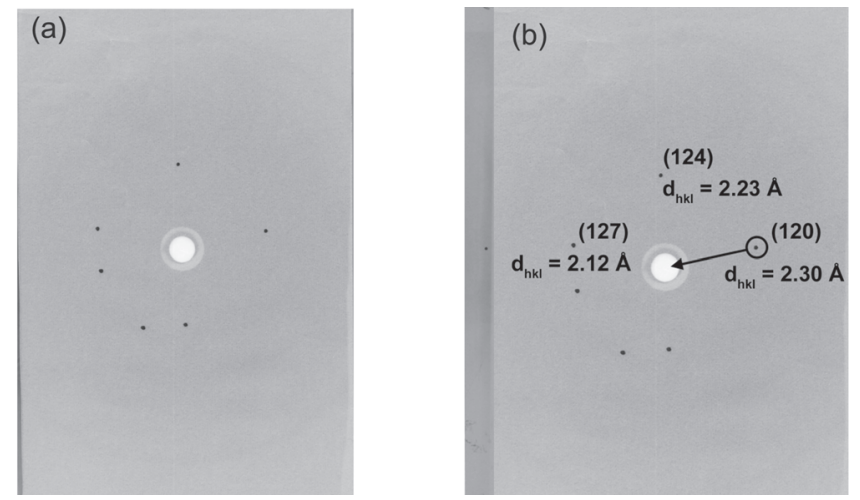

Figure 7. Film of $\mathrm{Cu}-\mathrm{Zn}$-Al single crystal alloy submitted to a tensile force of 8 tons, obtained using nickel filter (monochromatic radiation, $\lambda=1.54 \AA$ ) (a) and diffraction spot with (hkl) index of (120) placed in the center of the film to orientate the single crystal (b)

In Figure $7 \mathrm{~b}$ the circled spot of the lauiegram corresponds to a $(\mathrm{hkl})=(120)$, as can be demonstrated by the calculation shown below. From Figure $7 \mathrm{a}$, the distance (r) between the center of the film and the corresponding circled spot (Figure 7b) is $2.45 \mathrm{~cm}$, from eq. 3 the $\tan (2 \theta)=0.82$ and $\theta=19.67^{\circ}$. From Equation 4 the following $\mathrm{d}_{(\mathrm{hkl})}$ value is obtained:

$\mathrm{d}_{\text {(hkl) }}=\frac{\lambda}{2 \sin \theta}=\frac{1.54 \AA}{2 \sin (19.67)}=\frac{1.54 \AA}{0.67}=2.30 \AA$

This value $(2.30 \AA)$ is the closest value to $2.28 \AA$, which corresponds to the (120) plane. The Laüegram obtained after moving the circled spot (Figure $7 \mathrm{~b}$ ) to the center of the film is shown in Figure 8 . In the next steps Figure 8 was compared with the theoretical projection (Figure 2): it was observed that the (120) plane is $30^{\circ}$ from the $(010)$ plane, and both are located in the equatorial zone. As the goniometer does not allow the rotation of the crystal in the equatorial plane, it was manually rotated around its vertical axis and then the (010) crystallographic plane was orientated. The [010] direction coincides with the crystallographic axis of $b$ and is perpendicular to the (010) plane. The [010] direction is either a binary axis or it is contained in a symmetry plane, being the (010) plane very important due to its low Miller index.

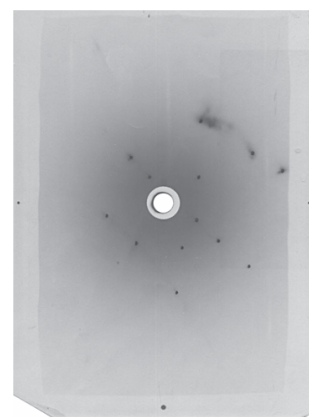

Figure 8. Laüegram obtained for $\mathrm{Cu}-\mathrm{Zn}$-Al alloy single crystal submitted to a tensile force of 8 tons, obtained without filter, and placing the corresponding spot in the direction of the (120) plane

When the (010) crystallographic plane was orientated the laüegram of the martensitic $\mathrm{Cu}-\mathrm{Zn}-\mathrm{Al}$ single crystal submitted to tensile force was obtained and its spots were not well defined (Figure 9a). In Figure 9b the corresponding stereographic projection is shown. This orientation, from the crystallographic viewpoint, is important because it coincides with a binary symmetry axis or a plane, which is the only one observed in the $b$ direction for monoclinic systems $\left(a \neq b \neq c\right.$ and $\alpha=\gamma=90^{\circ}$ and $\left.\beta \neq 90^{\circ}\right)$.

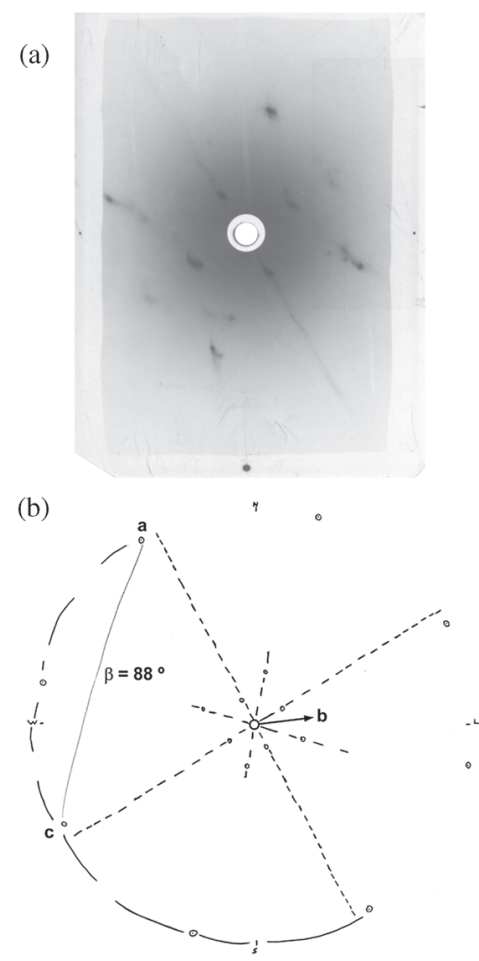

Figure 9. Laüegram (a) and stereographic projection (b) for martensitic Cu$\mathrm{Zn}$-Al alloy single crystal submitted to tensile stress and orientated in the direction of the (010) plane

The diffraction spots in the (120) plane are well defined (Figure 8), while this is not for the (010) plane (Figure 9a). It seems that a higher tension occurs more in the (010) plane than in the (120) one due to the stretching suffered by the (010) plane when the sample was submitted to tension stress. 


\section{CONCLUSIONS}

The possibility of orientation of a single crystal belonging to a low symmetry system, such as the monoclinic one, without the use of any sophisticated method or software was demonstrated. For martensitic single crystal $\mathrm{Cu}-\mathrm{Zn}-\mathrm{Al}$ alloy submitted to a tension of $8 \mathrm{t}$ the following crystallografic orientations were obtained: (010), (120) and (130).

The elongated spots in the lauiegram indicated that the higher tension stress was applied in the [010] direction when compared to the [120] one causing a stretching in the (010) plane, i.e., the single crystal was deformed in the (010) set of planes.

\section{SUPPLEMENTARY MATERIAL}

Supplementary Material desribes the Laüe Camera and goniometer and their use are in http://quimicanova.sbq.org.br, in PDF file.

\section{ACKNOWLEDGEMENTS}

The authors would like to thank FAPESP - Fundação de Amparo à Pesquisa do Estado de São Paulo (Proc. 01/11836-5) and CNPq - Conselho Nacional de Desenvolvimento Científico e Tecnológico (Proc. no. 300343/04) for the scholarships provided.

\section{REFERENCES}

1. Nakazato, R. Z.; Sumodjo, P. T. A.; Benedetti, A. V.; Portugaliae Electrochim. Acta 1987, 5, 263.

2. Cabot, P. L.; Centellas, F. A.; Garrido, J. A.; Sumodjo, P. T. A.; Benedetti, A. V.; Nakazato, R. Z.; J. Appl. Electrochem. 1991, 21, 446.

3. Benedetti, A. V.; Nakazato, R. Z.; Sumodjo, P. T. A.; Cabot, P. L.; Centellas, F. A.; Garrido, J. A.; Electrochim. Acta 1991, 36, 1409.

4. Hurtado, M. R. F.; Sumodjo, P. T. A.; Benedetti, A. V.; J. Electrochem. Soc. 1993, 140, 1567.

5. Moreira, A. H.; Benedetti, A. V.; Cabot, P. L.; Sumodjo, P. T. A.; Electrochim. Acta 1993, 38, 981 .
6. Benedetti, A. V.; Sumodjo, P. T. A.; Nobe, K.; Cabot, P. L.; Proud, W. G.; Electrochim. Acta 1995, 40, 2657.

7. Hurtado, M. R. F.; Ferrer, J. C.; Adorno, A. T.; Sumodjo, P. T. A.; Benedetti, A. V.; Electrochemical Society Proceedings, Pennington: NY, 1998, PV. 97-26, p. 665

8. Rosatto, S. S.; Cabot, P. L.; Sumodjo, P. T. A.; Benedetti, A. V.; Electrochim. Acta 2001, 46, 1043.

9. Hurtado, M. R. F.; Sumodjo, P. T. A.; Benedetti, A. V.; Electrochim. Acta 2003, 48, 2791.

10. Noce, R.; Fugivara, C. S.; Barelli, N.; Benedetti, A. V.; Portugaliae Electrochim. Acta 2003, 21, 117.

11. Guilemany, J. M.; Gil, F. J.; Miguel, J. R.; Revista Metalurgia de Madrid 1988, 24, 175.

12. Blanco, M.; Barelli, N.; Flor, S. W. A.; Benedetti, A. V.; Quim. Nova 2003, 26, 757

13. Hamelin, A. In Modern Aspects of Electrochemistry; Conway, B. E.; White, R. E.; O’Bockris, J., eds.; Plenum Press: New York, 1985, n. 16, ch. I.

14. Blanco, M.; Barelli, N.; Fugivara, C. S.; Fernández, J.; Guilemany, J. M.; Benedetti, A. V.; Acta Microscopica Suplement A 2001, November, 195.

15. American Society for Testing and Materials; E82-91: standard test method for determining the orientation of a metal crystal. West Conshohocken: ASTM, 1996.

16. Ehlers, C. B.; Villegas, I.; Stickney, J. L.; J. Electroanal. Chem. 1990, 284, 403.

17. Guilemany, J. M.; Fernández, J.; Franch, R.; Adorno, A. T.; Benedetti, A. V.; J. Physique IV 1995, 5:C2, 361.

18. Guilemany Casadamon, J. M.; Fernández Gonzalez, J.; Franch Maestro, R.; Benedetti, A. V.; Adorno, A. T. V.; Br PI 9.502.356-9, 1995.

19. Guilemany, J. M.; Fernández, J.; Franch, R.; Benedetti, A. V.; Adorno, A. T. V.; Sp PI 9401789, 1994.

20. Otsuka, K.; Shimizu, K.; Int. Metals Rev. 1986, 31, 93.

21. Saburi, T.; Wayman, C. M.; Takata, K.; Nenno, S.; Acta Metallurgica 1980, 28,15 .

22. Delaey, L. E.; Cornelis, I.; Acta Metallurgica 1970, 18, 1061.

23. Wayman, C. M.; Bhadeshia, H. K. D. H. In Physical Metallurgy Part II; Cahn, R. W.; Haasen, P., eds; $4^{\text {th }}$ ed., Amsterdan: North-Holland, 1996, p. 1508.

24. ASM International; ASM handbook Metals Park, 1985, vol. 9, p. 668.

25. Cullity, B. D.; Elements of $X$-ray diffraction, $2^{\text {nd }}$ ed., Addison-Wesley Publishing Company Inc: New York, 1978.

26. Maurice, V.; Yang, W. P.; Marcus, P.; J. Electrochem. Soc. 1996, 143, 1182.

27. Maurice, V.; Yang, W. P.; Marcus, P.; J. Electrochem. Soc. 1998, 145, 909.

28. http://www.public.asu.edu/ bdegreg/Xtalplanes.html, accessed in January 2005. 


\section{LAÜE BACK-REFLECTION METHOD FOR CRYSTALLOGRAPHIC ORIENTATION OF A MARTENSITIC Cu- Zn-AI SINGLE CRYSTAL OF THE MONOCLINIC SYSTEM}

Uíslei Carlos Zambrano, Matildes Blanco, Nilso Barelli and Assis Vicente Benedetti*

Departamento de Físico-Química, Instituto de Química, Universidade Estadual Paulista, CP 355, 14801-970

Araraquara - SP, Brasil

\section{Javier Fernández}

CPT Thermal spray Center, Materials Engineering, Dept. Ciencia dels Materials y Enginyeria Metal-lúrgica, Universitat de Barcelona, C/ Martí i Franqués 1, E-08028 Barcelona, Spain

A Laüe camera (Figure 1S) and a goniometer (Figure 2S) were constructed in the precision mechanical laboratory of Chemistry Institute of São Paulo University at São Carlos, based on a schematic diagram provided by Prof. A. Hamelin. The Laüe camera consists of a collimator system with $6 \mathrm{~cm}$ length and a hole with $1 \mathrm{~mm}$ diameter in the center (c) followed by a support for the film (b) totally protected from the light (the hole in the center of the support indicated by $\mathbf{d}$ must be sealed preferably with a metallic head). The goniometer, placed inside the piece indicated by a and a', holds the sample in the desired position and has a large angular freedom degree $\left(18^{\circ}\right)$ in $\mathrm{X}$ and $\mathrm{Y}$ axes. The crystal is fixed by Teflon pieces to the goniometer and placed $3 \mathrm{~cm}$ far from the film.
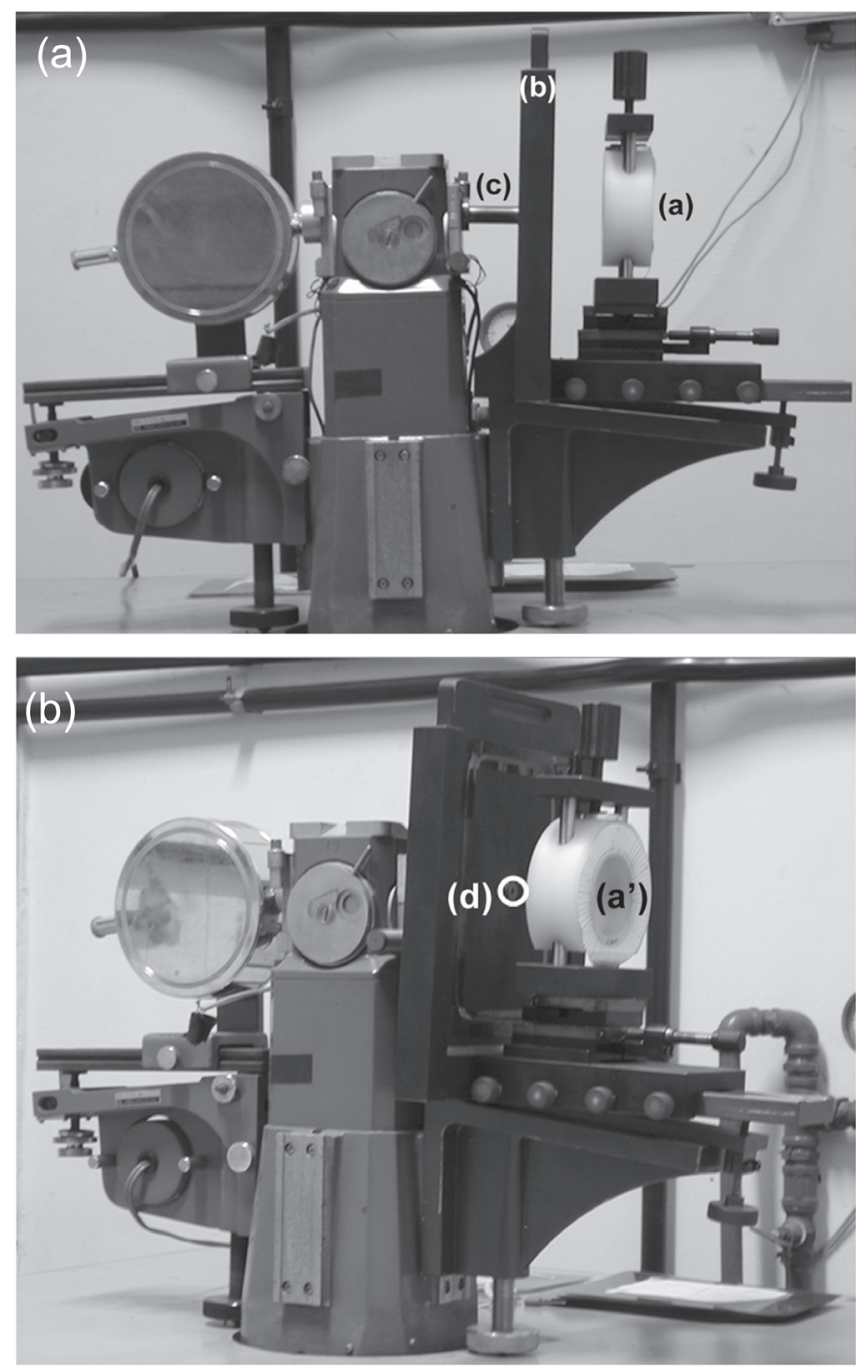

Figure 1S. Profiles of the X-ray camera used for crystallographic orientation. Support of the goniometer (a, and $\left.\boldsymbol{a}^{\prime}\right)$; film holder (b); trajectory of the X-ray beam going to the crystal (c); X-ray collimator (d) 

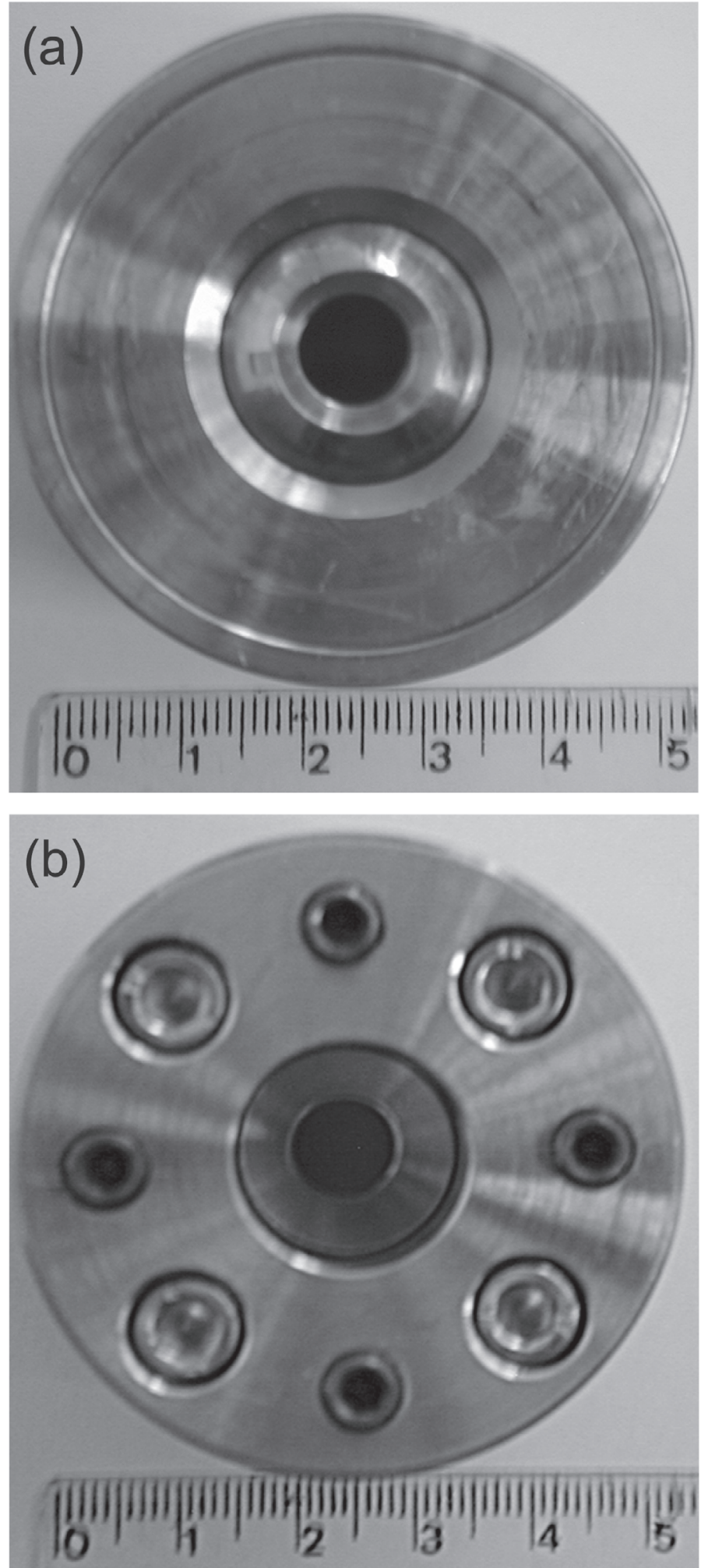

Figure 2S. Illustrative photos of the goniometer used in crystallographic orientation assays of the single crystal. (a) Front and (b) Backside of the goniometer: the smaller screws are used to provide the needed freedom degree for the angular movement 